\title{
TRATAMENTO EM UM GRUPO OPERATIVO EM SAÚDE: percepção dos usuários de álcool e outras drogas ${ }^{a}$
}

\author{
Paulo Barrozo CASSO L', M arlene Gomes TERRAc, Sadja Cristina T assinari de Souza M OSTARDEIROd, \\ M ariam de Oliveira G ON ÇA LVE Se, U rsula M aria Stockmann PIN H E IRO ${ }^{f}$
}

\section{RESUMO}

Pesquisa qual itativa que objetivou descrever a percepção de usuários de ál cool e outras drogas acerca do seu tratamento em um grupo operativo voltado ao ensino-aprendizagem em saúde. U tilizou-se a entrevista semi-estruturada com 16 usuários de álcool e outras drogas participantes de um grupo operativo realizado, no período de janeiro a março de 2010, em um hospital de ensino da região sul do país. Os depoimentos dos usuários foram interpretados mediante a A nál ise de Conteúdo T emática, desvel ados em duas categorias: percepção das per das resultantes do uso de álcool e outras drogas e percepção do grupo operativo em relação ao seu tratamento. Os resultados apontar am que o grupo pode contribuir para o processo de abstinência e inserção social desses usuários e a importância do enfermeiro coordenar grupos em saúde mental.

D escritores: T ranstornos relacionados ao uso de substâncias. P rocessos grupais. U suários de drogas.

\section{RESUMEN}

Investigación cualitativa que tuvo por objetivo describir la percepción de los usuarios de alcohol y otras drogas con su tratamiento en un grupo operativo vol cado a la enseñanza del aprendizaje en salud. U tilizó la técnica de la entrevista casi estructurada con 16 personas usuarias de al cohol y otras drogas y partici pantes de un grupo operativo realizado en el período de enero a marzo de 2010, en un hospital de enseñanza de la región del sur del país. L os testimonios de los usuarios han sido inter pretados mediante el A nálisis de Contenido T emático, dividido en dos categorías: percepción de las pérdidas resultantes del uso de alcohol y otras drogas y percepción del grupo operativo en relación a su tratami ento. L os resultados revelaron queel grupo puede contribuir para el proceso de abstinencia e inserción social de estos adictos y la importancia del enfermero en coordinar grupos de salud mental.

D escriptores: T rastornos relacionados con sustancias. Procesos de grupo. Consumidores de drogas. T ítulo: 0 perativos de tratamiento en un grupo en la salud: la percepción de los usuarios de al cohol y otras drogas.

\section{ABST RACT}

This is a qualitative research which aimed to describe how users of alcohol and other drugs perceive their treatment in an operational group focused on teaching-learning health care A semi-structured interview was conducted with 16 users of alcohol and other drugs who participated in an operational group that took place from I anuary to $M$ arch, 2010, in a teaching hospital in Southern B razil. T he users' testimonials w ereinter preted according to T hematic C ontent A nalyses, which revealed tw o categories: perception of the losses resultant of the use of alcohol and other drugs and perception of the operational group regarding their treatment. R esults show ed that the group can contribute to the abstinence process and the social inclusion of these users, and al so highlighted the importance of the nurse in the coordination of mental health care groups.

D escriptors: Substance related disorders. G roup processes. D rug users.

T itle: T reatment in a health care operational group: how it is perceived by users of alcohol and other drugs.

\footnotetext{
${ }^{a}$ A rtigo originado do T rabal ho de Conclusão do Curso de G raduação em E nfermagem da U niversidade Federal de Santa M aria (U F SM ), apresentado em 2010.

${ }^{\circ}$ Enfermeiro, E specializando do Programa de Pós-G raduação em E ducação A mbiental da U F SM , Santa M aria, Rio Grande do Sul, Brasil.

' D outora em E nfermagem, Professora A djunta do D epartamento e da Pós-G raduação em Enfer magem da U FSM, Santa M aria, Rio G rande do Sul, Brasil.

d D outora em Enfermagem, Professora A djunta do D epartamento de Enfermagem da U F SM, Santa M aria, Rio G rande do Sul, Brasil.

e Enfermeira, Especialista na M odalidade Residência em Saúde M ental Coletiva pela Escola de Saúde Pública, Porto Alegre, Rio G rande do Sul, Brasil.

f Enfer meira, M estranda pelo Programa de Pós-G raduação em Enfermagem da U F SM, Santa M aria, Rio G rande do Sul, Brasil.
} 


\section{INT RODUÇÃO}

0 uso de substâncias psicoativas pelo ser humano data desde os períodos anteriores ao neolítico, quando a humanidade aprendeu a selecionar os produtos da flora e a descobrir os que podiam ser úteis como alimentos e os de múltiplos usos substâncias atual mente denominadas de drogas e que abrangem embriagantes, remédios, estimulantes, sedativos e alucinógenos ${ }^{(1)}$. E ssas substâncias serviam para modificar o estado de consciência do homem em cerimônias tanto sagradas como profanas. Com o passar dos séculos o uso das drogas variou conforme a cultura e o grau de desenvolvimento das civilizações. Algumas substâncias, como 0 álcool, por exemplo, atingiram o estado de legalidade e se incorporaram aos hábitos sociais. Enquanto outras se tornaram ilícitas (2).

Do ponto de vista jurídico, as drogas podem ser classificadas em lícitas, que são aquelas comercializadas de forma legal, podendo ou não estar submetidas a algum tipo de restrição; e, as ilícitas, que são substâncias proibidas por lei. Outra forma de classificação das drogas baseia-se nas ações que elas exercem sobre o Sistema N ervoso Central, a partir das modificações observáveis na atividade mental ou no comportamento do indivíduo que as utiliza. Assim, as substâncias psicoativas podem ser classificadas em drogas depressoras, estimulantes ou perturbadoras da atividade men$\operatorname{tal}^{(3)}$.

N esta esteira, droga é qual quer substância não produzida pelo organismo humano que tem a propriedade de atuar sobre um ou mais sistemas, produzindo alterações em seu funcionamento. As alterações fisiológicas ou comportamentais ocasionadas pelo uso de substâncias psicoativas podem acarretar prejuízos à saúde humana, tais como: intoxicações, síndrome de abstinência, estados confusionais, demências, psicoses, distúrbios do humor, abuso e dependência de drogas(3).

A dependência de drogas está descrita como um conjunto de sintomas cognitivos, comportamentais, psicológicos e fisiológicos que indicam perda do controle sobre o uso da substância psicoativa e um uso continuado desta apesar dos problemas significativos relacionados à dro$\mathrm{ga}^{(3,4)}$.

0 tratamento da dependência química em saúde mental envolve a desintoxicação do usuá- rio, o fortal ecimento de seus hábitos saudáveis e 0 desenvolvimento de suas habilidades pessoais e sociais para a reintegração $\$$ à vida familiar e social. N este entendimento, cabe destacar que as atividades terapêuticas desenvolvidas pela enfermagem, em especial pelo enfermeiro, contemplam a real ização de reuniões, vistas domiciliar es, oficinas ter apêuticas e g rupos oper ativos com pacientes e/ ou seus familiares ${ }^{(3,5,6)}$.

É importante assinalar que os grupos operativos abrangem os campos comunitários, institucionais, terapêuticos e do ensino-aprendizagem. $\mathrm{N}$ esta última modalidade, a premissa fundamental é "aprender a aprender" e "mais importante do que encher a cabeça de conhecimentos é for mar cabeças"(7). D essa forma, essa aprendizagem relaciona-se a uma modalidade de pensamento que busca o conhecimento situado em seu contex to histórico e visa a criatividade e a transfor mação da realidade. E m consonância, essa ideia também remete ao "aprender a conhecer", um dos pilares da educação cuja finalidade é ter o prazer de compreender, de conhecer o mundo que nos cerca para viver dignamente ${ }^{(5)}$.

A essência dos grupos operativos de ensinoaprendizagem está pautada nos pressupostos de Enrique Pichon-Rivière, psiquiatra e psicanalista argentino, que definiu o grupo operativo como 0 conjunto de pessoas ligadas entre si por constantes de tempo e espaço, articuladas por sua mútua representação interna, que se propõe de forma explícita ou implícita a uma tarefa, constituindo-se na sua finalidade. Essa interligação dos integ rantes do grupo ocorre por meio dos sentimentos de pertinência (é o "vestir a própria camiseta") e de pertencência (o indivíduo se refere ao grupo como sendo "o meu grupo") que os une em torno de uma tarefa e de um objetivo comum ${ }^{(6,7)}$.

A coordenação de grupos operativos voltado ao ensino-aprendizagem dos pacientes dependentes de substâncias psicoativas é um desafio a enfermagem, pois à luz dos pressupostos pichonianos, o coordenador é aquele que pensa com o grupo e mantém o foco na tarefa proposta ${ }^{(7)}$. A partir desse entendimento, constitui-se como questão de pesquisa: qual é a percepção dos usuários de álcool e outras drogas acerca do seu tratamento em um grupo operativo de ensino-aprendizagem? E, como objetivo geral: descrever a percepção dos usuários de álcool e outras drogas acerca do seu tratamento em um grupo operativo. 


\section{MET OD OLOGIA}

Pesquisa que se caracteriza por ser qualitativa-descritiva porque o fenômeno estudado é complexo e de natureza social, envolvendo o entendimento do contexto social e cultural. Essa abordagem constitui-se de uma interpretação do que os sujeitos falam e expressam, pois para a compreensão do objeto de pesquisa necessita-se compreender 0 contexto ao qual está inserido(8).

Trata-se de um artigo originado de um trabal ho de conclusão de curso ${ }^{(9)}$, o cenário do estudo foi uma unidade para tratamento de dependentes químicos de um hospital de ensino da região sul do país que atende pacientes do sexo masculino e feminino maiores de dezoito anos. 0 critério de inclusão foi: ser usuário e estar participando em um grupo operativo de ensino-aprendizagem realizado na referida unidade. Foram excluídos os usuários que não se adequaram ao critério estabelecido.

Assim, constituíram-se sujeitos da pesquisa 16 usuários de álcool e outras drogas (13 do sexo masculino e três do sexo feminino), que participaram nos grupos no período de janeiro a março de 2010. Conforme, o que já foi mencionado, trata-se de uma pesquisa qualitativa e por ser intencional cessam as entr evistas quando o pesquisador observa consistência das infor mações ${ }^{(8,10)}$.

A faixa etária das participantes do sexo feminino situou-se entre cinquenta e dois a sessenta e dois anos e a do sexo masculino de trinta e um a cinquenta e oito anos. Em relação às substâncias utilizadas pelos participantes, o uso de álcool foi 0 mais consumido (16 participantes), cocaína (três participantes) e maconha (três participantes). Quanto ao número de internações, um dos participantes não teve internação hospitalar e os demais variaram de uma a oito inter nações. Quanto ao tempo de frequência no grupo de apoio variou de três meses a dezessete anos. Em relação ao grau de instrução, observou-se que os participantes apresentavam ensino fundamental incompleto (quatro); ensino fundamental completo (dois); ensino médio incompleto (dois), ensino médio completo (quatro); ensino pós-médio ou técnico (três); graduação somente um. Quanto ao Estado civil, nove eram casados (as)/ companheiros (as); seis eram solteiros (as)/ separados (as) e um não declarou seu estado.

A coleta de dados foi real izada por meio da entrevista semi-estruturada que valoriza a presença do pesquisador, proporciona espontaneidade e liberdade do sujeito de pesquisa ${ }^{(8,11)}$. Optou-se também pela utilização do diário de campo a fim de registrar as observações realizadas pelo pesquisador. A pós aprovação da pesquisa pelo Comitê de Ética em Pesquisa com Seres Humanos da U niversidade Federal de Santa M aria pelo Parecer $\mathrm{n}$ 0.316.0.243.000-09, iniciou-se a coleta de dados. A ssim, os participantes for am convidados pelo pesquisador a participar da entrevista semi-estruturada e, após, aceite dos sujeitos da pesquisa, solicitou-se a assinatura do Termo de Consentimento Livre e Esclarecido (T CLE) o qual informava que el es for am esclarecidos sobre a pesquisa e que concordavam em colaborar voluntariamente. E m todo o processo de pesquisa foram observados os pressupostos éticos da Resolução 196/ 96 do Consel ho Nacional de Saúde ${ }^{(12)}$.

A entrevista semi-estruturada foi gravada e iniciou com as seguintes questões: durante seu tratamento no grupo como foram abordadas as questões sobre dependências de substâncias psicoativas? A s explicações sobre álcool e outras drogas estão esclarecendo? Foi utilizado um gravador digital, para que o pesquisador conseguisse dar maior atenção, não tendo que anotar tudo. $M$ as, caso o participante desejasse, o gravador não seria utilizado. É importante ressaltar que as identidades dos participantes foram preservadas em todas as etapas da pesquisa adotando-se a letra "P" (P1, P 2, P 3,...) por ser a letra inicial da palavra participante.

A pós a entrevista, os depoimentos foram transcritas em forma de texto e as informações foram organizadas e submetidas à análise de conteúdo temática ${ }^{(8)}$. Este método propõe três etapas para análise dos resultados: a pré-análise, a exploração do material e a interpretação.

A pré-análise caracteriza-se por ser dividida em três subfases: a leitura flutuante, a constituição do corpus e a formulação e reformulação de hipótese e objetivos. N esta etapa, realizaram-se várias leituras, exaustivamente, do material obtido na etapa anterior tendo como parâmetro a questão norteadora da pesquisa ${ }^{(8)}$.

$\mathrm{N}$ a fase de exploração do material, iniciou-se a construção de unidades de registro, de contexto, segmentos significativos e temas por meio de uma leitura que buscava extrair a essência do texto. Assim, a partir desta leitura, obteve-se o recorte dos elementos comuns aos conteúdos dos materiais e a construção das categorias. N esta pes- 
quisa, as categorias não foram pré-determinadas, porém foram definidas conforme os depoimentos dos participantes. A fase de tratamento dos resultados obtidos e interpretação contemplou a etapa de indução de significados e interpretação do conteúdo recortado segundo o referencial teórico adotado. N este momento, procurou-se articular a informação presente nas unidades de registro com as impressões advindas das entrevistas para que 0 produto final desta fase fosse o mais próximo possível da intencionalidade dos participantes ${ }^{(8)}$.

\section{RESULTADOS E DISCUSSÃO}

A partir da leitura e interpretação do conteúdo das entrevistas transcritas, juntamente com as observações real izadas durante as mesmas, realizou-se a análise dos conteúdos dos depoimentos dos sujeitos de acordo com o referencial teórico pertinente. $\mathrm{N}$ a fase de exploração do material desvelaram-se duas categorias: percepção das perdas resultantes do uso de álcool e outras drogas e percepção do grupo operativo de ensino-aprendizagem em relação ao seu tratamento.

\section{Percepção das perdas resultantes do uso de álcool e outras drogas}

Os participantes relataram que o uso do álcool e outras drogas é um processo caracterizado por perdas intensas sendo consequências de suas ações. E ssa percepção de que as drogas afetam todo seu viver de forma negativa provoca sentimentos referentes à consciência dos prejuízos causados pelas drogas, tanto na vida pessoal e familiar quanto na esfera social, do trabalho e na sua própria dimensão moral. As sequelas envolvem as suas economias e lares desfeitos ao por em riscos os valores morais, a saúde e a ordem pública(13). Isto pode ser observado nos depoimentos a seguir.

[ ...] coisas boas não trás nada. D esgraça leva bens materiais, moral da pessoa, família (P 9).

[ ...] é uma destruição! Família, primeiro que adoece [ ...] destruição termina com a moral da gente Vai lá em baixo a moral. Álcool eas drogas [ ...] a moral vai lá embaixo, nossa! (P6).

Com o passar do tempo o usuário também começa a sentir as consequências do uso de drogas em relação a sua saúde. 0 abuso de drogas acarre- ta ao indivíduo inúmeros prejuízos com reflexos em suas relações profissionais, interpessoais, familiares e em sua saúde ${ }^{(14)}$. Essa percepção pode ser visualizada nos seguintes depoimentos:

[ ...] para mim acho que éum veneno (P7).

[...] ah! Ás vezes dava problema de ataque de nervos (P8).

[...] entendo que faz mal pra gente, faz mal (P11).

[ ...] causam lesões em todo sentido: cerebral, física (P13).

Percebe-se, dessa forma, que os participantes reconhecem os efeitos negativos do uso do álcool e outras drogas em sua saúde comparando a um veneno que ocasiona diversas lesões em seu corpo. Quando o usuário sente os inúmeros prejuízos na sua vida, começa a perceber o quanto é forte a sua dependência em relação a elas. N este momento, percebe como é difícil parar ou controlar o consumo das drogas.

[ ...] causa dependência! Álcool, cocaína é muito difícil, mudar o quadro. Várias internações, para livrar disso ai [ ...] dependência traiçoeira com a gente mesmo (P1).

[ ...] entendo que é ruim, que viciam, que causam dependência (P2).

[ ...] vai ter pessoas que vai ter uma deficiência. E u sei lá se é uma questão fisiológica ou questão hereditária quenão vai poder beber. É um dependentequímico (P10).

[ ...] como équevou dizer, assim, éuma substância que o meu organismo se acostumou. E, eu édifícil de conseguir controlar. Quando vem, quando dá fortea vontade (P12).

[ ...] o vicio ébrabo! N ão éfácil delargar. E u já tentei muitas vezes (P14).

[ ...] uma coisa quea pessoa adquire, de agir, ficar dependente [ ...] eu tenho consciência que não posso ingerir mais nada. Porque se eu ingerir um gol e eu não paro (P 16).

A pesar dos inúmeros prejuízos causados por abuso de drogas, os indivíduos continuam com seu uso, o desejo de consumir a substância é muito for- 
te. Pelos depoimentos dos participantes percebemse as tentativas frustradas de interromper ou diminuir seu uso, pois fugiu ao seu controle, não consegue mais parar o seu uso, mesmo com internações hospitalares.

\section{Percepção do grupo operativo de ensino- aprendizagem em relação ao seu tratamento}

No grupo oper ativo desenvolvido na unidade psiquiátrica percebe-se a partir dos depoimentos dos participantes a função continente exercida pelo campo grupal, pois os próprios usuários denominam esse grupo como "de apoio". Essa denominação parte da possibilidade que os pacientes encontraram de compartilhar com o grupo suas experiências, seus conflitos, suas perdas, suas recaídas e suas vitórias. Assim, um grupo coeso e bem constituído exerce a importante função de ser continente das angústias e necessidades de cada um e de todos os membros ${ }^{(7)}$. N esse sentido, a percepção dos participantes está expressa nos depoimentos a seguir:

[ ...] o meu tratamento aqui no grupo de apoio émuito bom. E u percebo que tem me ajudado bastante [ ...] 0 nome mesmo já diz grupo de apoio. Onde a gente tem bastante apoio (P3).

\section{[ ...] porque sem o grupo tu não tens apoio (P 13).}

[ ...] o nome é cer to, apoio (P 16).

[ ...] importantíssimo! Porque sem o grupo de apoio tu não tens condi ções de chegar aonde cheguei (P6).

A vivência grupal pode prevenir a recaída e as trocas de experiências entre os membros podem estimular reflexões e conduzir a elaboração de dificuldades pessoais, pois a composição homogênea do grupo (pessoas reunidas em torno de uma situação em comum) favorece a identificação e, em consequência, a coesão(15). Dessa forma, ocorre um fortalecimento pessoal frente às drogas e outras situações da vida pessoal levando além da abstinência também a reestruturação pessoal.

[ ...] eu vejo que é muito bom em relação a minha doença. [ ...] as outras vez es que eu estive internado não segui nenhum grupo de apoio, nem Alcoólicos A nônimo. $N$ unca deu certo por mais que eu tentasse, mas não. É fundamental o grupo de apoio (P1).
[ ...] meajuda muito sentir a pessoa que ouviu o queeu falei. [ ...] e então, ontem melembrei de ti. Foi interessante 0 que tu falou aquilo ali me ajudou (P8).

[ ...] ajuda bastante, tanto é que fiquei três finais de semana sem vir e tive uma recaída (P12).

[ ...] no grupo é onde se fala exatamente aquilo que tu sentes. [ ...] se está bem, seestá mal, seestá com raiva, se está triste, se está alegre, se está com vontade de beber se não está. Para os outros não adianta. 0 s outros não vão entender (P 13).

A principal tarefa desse grupo operativo de ensino-aprendizagem é 0 alcance e a manutenção da abstinência das drogas pelos pacientes. É em torno dessa tarefa que os usuários estão reunidos no grupo e interligados por um objetivo coletivo. Cabe salientar que embora aparentemente simples a tarefa, esse processo implica crescimento pessoal e mudança no cotidiano das pessoas envolvidas para 0 al cance e manutenção da abstinência. Para tanto, a atitude fundamental a ser desenvolvida com o grupo é a de que os seus membros "aprendam a aprender", ou seja, possa-se aliar ao propósito da informação 0 da formação, principal mente no que se refere à aquisição de atitudes inter nas por el es ${ }^{(5-7)}$. A ssim, durante a realização dos grupos oper ativos de ensino-aprendizagem buscou-se informar os usuários acerca dos efeitos e conseqüências do uso de drogas à saúde humana a fim de mobilizar recursos internos para maior autonomia e consciência desses sujeitos.

Os participantes referiram as suas percepções lembrando os momentos compartilhados com outros participantes no grupo de apoio. Alguns depoimentos ilustram, a seguir:

[ ...] sim, esclarecendo de várias drogas. F or nece muita informação (P1).

[ ...] foi esclarecendo. N ão sou muito defalar, mas fico captando o que cada um fala (P2).

[ ...] acho que foram abordadas assim de todas as maneiras [ ...] esclarecem sim. Isso até ajuda bastante a gente (P3).

[ ...] todas elas explicando o funcionamento, o prejuízo ea forma prejudicial (P4).

[ ...] estão esclarecendo A gora estou entendendo (P 5).

[ ...] aos poucos, a gente vai ouvindo opiniões diferentes evai esclarecendo, vai abrindo as idéias (P6). 
[ ...] estão esclarecendo inclusivea gente estudou muito 0 corpo humano ai (P16).

0 entendimento por parte dos usuários, de que sofrem um processo de doença que é a dependência química pode ajudá-los no al cance e na manutenção de sua abstinência. E ssas infor mações são importantes porque podem auxiliá-los em seu autoconhecimento e um indivíduo bem esclarecido está apto a tomar decisões mais conscientes. $N$ esse sentido, o coor denador deve assumir uma postura ativa, apoiando, reassegurando e informando por meio de indagações, correlações ou reflexões sem perder o foco na tarefa grupal(15), bem como desenvolver postura crítica-reflexiva que possibilite 0 acompanhamento dinâmico da realidade ${ }^{(16)}$.

Ainda, durante as participações no grupo operativo de ensino-aprendizagem, dois usuários relataram sobre as facilidades encontradas no tratamento, o acol himento recebido e o gosto de ajudar o outro:

[ ...] facilidade que eu tenho para me expressar etambém gosto muito de ajudar de ajudar os outros (P8).

\section{[ ...] facilidade 0 acolhimento a recepção (P 10).}

Por outro lado, cinco participantes expressaram algumas dificuldades encontradas no decorrer do seu tratamento, tais como: meio de transporte pel o valor el evado, horário do trabal ho ser o mesmo do grupo e por não gostar de falar, mas de ouvir.

[ ...] é um pouco o transporte, são dez reais para vir (P1).

[ ...] a maior dificuldademinha agora para vir no grupo éo horário do trabalho (P3).

[ ...] é eu tenho um pouco porque eu moro longe Às vez es, não tenho dinheiro, às vezes, não consigo transporte da prefeitura (P9).

\section{[ ...] só não venho se não quero (P 13).}

[ ...] a dificuldadequetenho édefalar pouco. [ ...] não sou muito de falar, mais de ouvir, ouvindo (P 14).

Entre as dificuldades decorrentes da psicodinâmica dos participantes precisam ser encaradas a utilização de mecanismos defensivos, pois os usuários inviabilizam, diversas vezes, a utilização de re- cursos disponíveis para alcançar determinado objetivo ter apêutico. Com frequência, el es mostram-se pouco cooperativos em relação às condutas necessárias para seu restabel ecimento bio-psíquico-social, evitando reconhecer e enfrentar suas dificuldades, mesmo com o agravamento, em diversos casos, de seu estado de saúde ${ }^{(1)}$. N esses casos, é importante o grupo estar alerta para mobilizar no indivíduo recursos que favoreçam sua vinculação ao tratamento confor me combinado com a equipe multidisciplinar. Para tanto, é necessário sensibilizá-lo para a participação em grupo.

\section{CONSIDERAÇÕES FINAIS}

N esta pesquisa buscou-se conhecer a percepção dos usuários de álcool e outras drogas acerca do seu tratamento em um grupo operativo de ensino-aprendizagem realizado na unidade psiquiátrica de um hospital escola da região sul do país.

Através dos depoimentos nesta pesquisa, constatou-se que os usuários de drogas concebem as substâncias psicoativas como um processo de perdas familiares, materiais, morais e a sua saúde, assim como algo que vicia que causa dependência. Os depoimentos sobre as perdas familiares e as separações demonstram que a família é algo especial, que foi perdida ou está sofrendo. Q uanto às perdas materiais está bem evidenciado como seu patrimônio, seu trabal ho, sua moral está arruinada, ou seja, é a destruição causada pela droga.

A importância da conscientização dos prejuízos a sua saúde é que muitas doenças podem estacionar ou retroceder quando cessar o uso de substâncias psicoativas, bem como as perdas familiares, materiais e sociais em uma compar ação entre o que o sujeito teve e o que perdeu. Entretanto, apesar dos inúmeros prejuízos causados pel o abuso de drogas, os indivíduos relatam que é difícil interromper o seu uso, pois o desejo de consumir a substância é muito forte. É de grande relevância para os profissionais de saúde que trabal ham com a questão da dependência química, conhecer essas percepções; pois abrem possibilidades, de trabalhar com a redução das consequências nos campos, social, econômico e na saúde, por refletirem com os usuários do grupo sobre as perdas produzidas pelo uso de álcool e outras drogas e isto pode se tornar um estímulo para o usuário continuar seu tratamento, bem como valorizar a abstinência.

0 valor do grupo operativo é reconhecido pel os seus membros quando o denominam "grupo 
de apoio", atribuindo a ele como sendo um importante suporte para manterem-se em abstinência, espaço para o diálogo, aprendizado e como responsável pelas vitórias conseguidas na luta contra o consumo de drogas. Essa val orização demonstra como essa modalidade pode contribuir com o serviço de saúde mental em relação à dependência química.

T ambém, por ser uma atividade grupal tem um baixo custo financeiro e ainda por ser uma forma de educação em saúde, pois educar para a saúde é ajudar o indivíduo na busca da compreensão das situações e problemas de saúde, assim como as de suas soluções. Sendo pautado no diálogo, um intercâmbio entre o conhecimento científico e o saber popular, valorizando cada um deles, como forma de ensinar e aprender, numa construção coletiva.

Concluímos que as percepções dos usuários de álcool e outras drogas apresentadas por essa pesquisa evidenciam o grupo operativo como uma ferramenta importante na manutenção do tratamento e sua inserção social num processo de abstinência, resultando assim em uma melhora em sua qualidade de vida, que reflete não apenas no indivíduo em si, mas também em seus familiares, amigos, no trabal ho e na sociedade em geral.

\section{REFERÊNCIAS}

1 Seibel SD. D ependências de drogas. 2ạ ed. São Paulo: A theneu; 2010.

2 Pratta E M M , Santos M A. 0 processo saúde-doença e a dependência química: interfaces e evolução. P sicol Teor Pesqui. 2009;25(2):203-11.

$3 \mathrm{~N}$ icastri S. D rogas: classificação e efeitos no organismo. In: M inistério da Justiça, Secretaria $\mathrm{N}$ acional de Políticas sobre D rogas. Prevenção ao uso indevido de drogas: capacitação para conselheiros elider anças comunitárias. 2ª ed. Brasília (DF ); 2010. p. 15-36.

$4 \mathrm{M}$ arot R. Classificação das doenças mentais: CID -10: trans. por substâncias psicoativas. Rio de Janeiro: Psicosite; [ 20--] [ citado 2011 maio 03] . Disponível em: http:/ / www.psicosite.com.br/ cla/ c_dep_qui.htm.

5 Simões FV, Stipp M AC. G rupos na enfer magem: classificação, terminologias e formas de abordagem. Esc

\section{E ndereço da autora / Dirección del autor / Author's address:}

$M$ arlene $\mathrm{G}$ omes Terra

Rua Felipe dos Santos, 97, M edianeira

97070-340, Santa M aria, RS

E-mail: martesm@ hotmail.com.br
A nna Nery [Internet] . 2006 [ citado 2011 abr 22] ; 10(1):139-44. Disponível em: http:/ / www.scielo.br/ pdf/ ean/ v10n1/ v10n1a19.pdf.

6 Cardoso ASF, M ielkeF B, Riboldi CO, Soares N V, Olschowsky A, Dall'A gnol CM . Coordenação de grupos na enfermagem: reflexões à luz de Pichon-Rivière. REM E: Rev M in Enferm. 2009;13(2):288-92.

7 Zimerman DE. Fundamentos básicos das grupoterapias. $2^{a}$ ed. Porto Aleg re: A rtmed; 2000.

8 M inayo M CS. 0 desafio do conhecimento: pesquisa qual itativa em saúde. 12ª ed. São Paulo: H ucitec; 2010.

9 Cassol PB. Tratamento em um grupo operativo em saúde: percepção dos usuários de álcool e outras drogas [ monografia]. Santa M aria: Centro de Ciências da Saúde, U niver sidade F ederal de Santa M aria; 2010.

10 T urato ER. Tratado da metodologia da pesquisa clínico-qualitativa: construção teórico-epistemológica, discussão comparada e aplicação nas áreas da saúde e humanas. 2aㅡ ed. Petrópolis: Vozes; 2003.

11 Triviños ANS. Introdução à pesquisa em ciências sociais: a pesquisa qual itativa em educação. São PauIo: Atlas; 1987.

12 M inistério da Saúde (BR), Consel ho N acional de Saúde, Comitê $\mathrm{N}$ acional de É tica em Pesquisa em Seres H umanos. Resolução 196, de 10 de outubro de 1996: diretrizes e normas regulamentadoras de pesquisa envolvendo seres humanos. Brasília (DF); 1996.

13 M inayo M CS, Coimbra Junior CE A. Críticas e atuantes: ciências sociais e humanas em saúde na A mérica Latina. Rio de Janeiro: F iocruz; 2005.

14 Carrillo PLL, M auro M Y CO. T rabal ho como fator de risco de proteção para o consumo de álcool e outras drogas. Texto Contexto Enferm. 2004;13(2): 217-25.

15 Campos E P. G rupos de suporte. In: Filho JM , organizador. G rupo e corpo: psicoterapia de grupo com pacientes somáticos. Porto A legre: A rtmed; 2000. p. $113-26$

16 Santos VOG, Vargens OM C. A prática discente na construção do conhecimento sobre o fenômeno das drogas. Rev G aúcha E nferm. 2010;31(1):41-7.

Recebido em: 22/ 07/ 2011

A provado em: 21/ 11/ 2011 